\title{
Delay of Gratification in Predicting Job Performance in New Employees: A Time-Varying Process and the Moderating Role of Perceived Informational Justice
}

\author{
Xiaoyan Liu ${ }^{1}$ and Kun Yu \\ ${ }^{1}$ College of Business Administration, Guangzhou University, Guangzhou, China \\ ${ }^{2}$ School of Labor and Human Resources, Renmin University of China, Beijing, China
}

\begin{abstract}
O ur study profiles a varying process of the relationship between delay of gratification (DG) and job performance over time and examines the moderating role of perceived organisational justice in the DG-job performance relationship. Employees' ability to delay gratification was measured during their job interviews (Time 1). When they had worked for 3 months (Time 2), their job performance was rated by their supervisors. When they had worked for 5 months (Time 3), their perception of perceived informational justice was measured. Their job performance was rated again by their supervisors at 6 months (Time 4). The results showed that DG could directly predict new employees' short-term (3month) job performance but not their longer-term (6-month) job performance. Moreover, perceived informational justice moderated the relationship between DG and 6-month job performance.
\end{abstract}

Keywords: delay of gratification, job performance, time-varying process, perceived informational justice, moderation

Delay of gratification (DG) refers to individuals' ability to forego immediate gratification in order to attain a more valuable outcome later on (Mischel, 1974) and is a useful strategy of self-regulation (Mischel, 1996; Mischel, Cantor, \& Feldman, 1996). It has been well documented that DG is important for lifelong development (see Ayduk, 2007, for review). For example, DG measured in childhood is an effective predictor of high academic performance more than 10 years later (Mischel, Shoda, \& Peake, 1988).

Although a lot of research has proved the positive and important role of DG on children's later academic performance (e.g., Duckworth \& Seligman, 2005; Shoda, Mischel, \& Peake, 1990), these findings cannot be generalised to the workplace. Employees' achievement is influenced not only by DG but also by many external situations, such as social support (Liu, Wang, \& Liao, 2016). Some research has found that when people know others will supervise or pay for their behavioural outcomes, even though they themselves are less motivated to overcome difficulties, they tend to conform and choose to pursue long-term benefit (Fishbach \& Trope, 2005). Therefore, there are likely to be some boundary conditions for the impact of DG on job performance. Moreover, although predicting long-term achievement is a core function of DG, to our knowledge, no research has examined longitudinally the role of DG in predicting long-term job performance, and the causal relationship between DG and job performance is unknown. Some researchers have found that self-regulation tactics such as intended effort and planning were positively related to both objective and subjective job performance (Porath \& Bateman, 2006; VandeWalle, Brown, Cron, \& Slocum Jr., 1999), but the effect of DG on job performance was not considered.

The current study contributes to the literature in part by adopting a longitudinal research design. With multiple data points, we examined the critical role of employees' DG in predicting job performance over time. In addition, the present study advances our understanding of the relationship between DG and job performance by testing the moderating role of perceived informational justice. A previous article has shown that the situational variable of seeing a reward may affect children's behaviour in pursuing more or less easily obtained long-term outcomes (Shoda et al., 1990). In the workplace, perceived 
informational justice as a situational factor might ensure that employees are treated fairly in their everyday organisational lives regarding promotion, salary, and social setting (Colquitt, 2001). Perhaps, then, perceived informational justice will also ensure that employees with higher DG will be motivated to work hard for greater success and bigger rewards in the future. To address this issue, we tested perceived informational justice as a moderator to examine a boundary condition for the DG-job performance relationship. Understanding the effect of perceived informational justice may help us know when 'delayers' are more or less willing to show better performance for future rewards in their organisation.

\section{Theoretical Background and Research Hypothesis \\ Delay of Gratification and Performance}

The most important feature of DG is that it can predict people's long-term academic performance, as demonstrated in the classic experiment by Mischel (1974) in which a child was left alone with two potential rewards an immediate but smaller reward, and a delayed but more valuable one. In a follow-up study, Mischel et al. (1988) found that the preschool children who had delayed longer in the experiment achieved higher Scholastic Assessment Test (SAT) scores 10 years later. Moreover, Duckworth and Seligman's (2005) research showed that students' selfdiscipline, which included DG, measured at the beginning of a semester could predict their final grade point average (GPA) and other academic engagement behaviour, such as fewer school absences.

We can explain the relationship between DG and longterm academic performance using self-regulation theory, which shows that people are different in their ability to resist temptation, and they weigh up the possible gains and losses of options for reaching long-term goals (Baumeister \& Vohs, 2003). DG is 'an important form of self-regulation because it requires overriding one's most pressing and salient impulse' (Baumeister \& Vohs, 2003, p. 203). In the previously noted study on self-regulation, Mischel and colleagues (1988) found that children who had been able to resist the temptation of a cookie at age 4 were, as adolescents, more attentive, more able to concentrate, and more likely to exhibit greater ability to cope with stress than their peers. These attributes may be an important reason why DG can predict academic performance over time.

However, compared to the large amount of research on the association between DG and academic performance, to our knowledge there are few cross-sectional studies examining the relationship between employees' DG and their job performance (Miller, Woehr, \& Hudspeth, 2002). In traditional industrial and organisational psychology literature, DG, as a personality trait or as one aspect of emotional intelligence (Lindebaum, 2013), is regarded as a moderator (Joy \& Witt, 1992; Witt, 1990) or nothing more than an additional dimension of work ethic (Miller et al., 2002). Therefore, it was necessary to carry out an empirical study to gain a comprehensive understanding of the effect of DG on job performance.

More importantly, the impact of DG on job performance may be a dynamic process over time, as prior evidence supports the idea that the relationship between various predictors and job performance is unstable over time (Henry \& Hulin, 1987). Murphy (1989) found that individual difference (e.g., cognitive ability) has a stronger influence in the transition stage, when employees are new to a job, than in the maintenance stage, when job tasks have been well learned by employees over a period of time after the transition. In other words, the predictive effect of individual difference (e.g., cognitive ability or personality) on job performance is most evident in novel job environments (Hesketh \& Neal, 1999) and weakens over time. Thus, the predictive effect of DG as an individual difference on performance would be weaker in the long run (i.e., sixth month) than during organisational entering. The current research endeavoured to empirically test how the effect of DG on performance weakens over time.

To this end, we specifically conducted our study with newcomers and rated employees' job performance at 3 months and 6 months. We posited that new employees' DG measured at their interview stage (Time 1) can predict their short-term job performance (Time 2, 3 months after Time 1). However, as the working time increases (Time 3, 6 months later), the unique role of DG in predicting long-term performance will be weakened, while situational factors may take on a more important role. Thus, we propose our first hypothesis:

Hypothesis 1: At the third month following new entry, employees' DG positively correlates with their job performance, whereas this relationship tends to be weaker at the sixth month.

\section{The Moderating Role of Perceived Informational Justice in the} DG-Job Performance Relationship

It is known that self-regulation can be impaired not only by individual factors, such as Down syndrome (Cuskelly, Airong Zhan, \& Hayes, 2003) and impulsivity (Strakowski et al., 2010), but also by situational factors. For example, when people know that others will supervise or pay for their behavioural outcomes, they exhibit more selfcontrol behaviours in order to obtain long-term benefits (Fishbach \& Trope, 2005). After exposure to the suffering of an innocent victim, participants who believed the world was not a just place where people get what they deserve had more desire for smaller, immediate rewards at the expense of larger, delayed rewards (Callan, Shead, \& Olson, 2009). The concept of organisational justice describes and explains the role of fairness in the workplace (Greenberg, 1990). It can help people feel valued by their authority figures and the group they belong to (Tyler \& Lind, 1992). We infer that if employees believe there is justice in the workplace, they will prefer long-term rewards and work 
hard. Accordingly, in the present study, we investigated justice as a moderator in the relationship between DG and long-term job performance.

Among types of justice, in this study we concentrated on perceived informational justice, which involves the extent to which supervisors explain rules and procedures at an appropriate time and in detail; it also assesses supervisor truthfulness (Colquitt, 2001). Our interest was the fairness of communication that may influence employees' long-term development in an organisation, rather than fairness of outcome allocations in the short term. Outcome allocations such as salary, bonuses and benefits, and the procedures used to determine their distribution can be clarified in a short time after a new employee entered company (Colquitt, Greenberg, \& Zapta, 2005). When facing short-term goals, people with either high or low DG may easily strive for the clear rewards (Mischel, 1974). Waiting for long-term goals, however, may involve more uncertainty and difficulties. In the long-term scenario, employees with a high level of DG can exert their advantage: resist temptation, tolerate the delay, practise patience, and cope with difficulties (Mischel et al., 1988). By providing adequate and honest communication, perceived informational justice influences the perceived fairness of how decisions are enacted (Bies, 2001; Bies \& Moag, 1986), as employees can better understand the rules and procedures for achieving long-term goals rather than only short-term distribution outcomes. The greater their expectation that the rewards will occur fairly, the harder employees will work in the organisation. Therefore, we examined information justice as a moderator between DG and job performance.

Three aspects of perceived informational justice are likely to influence the relationship between DG and job performance. First, evidence indicates that explaining knowledge or information about delay rules to children appears to predict their effective delay behaviour. For example, they waited longer when they knew how to distract themselves from the immediate reward (Mischel et al., 1988). We infer that when employees receive comprehensive explanations about procedures and rules for gains in the long run, such as getting promoted and developing a better career, they are inspired to devote themselves to the work. Second, in an organisation with perceived informational justice, supervisors are likely to explain rules and information to employees in detail as soon as the information is available (Colquitt, 2001), and therefore employees can be motivated by detailed knowledge such as position vacancies and promotion opportunities. Finally, previous research found that perceived trust and consideration of a leader will encourage individuals to spend more time on required tasks, as well as their willingness to go 'above and beyond' their job role (Konovsky \& Pugh, 1994).

Another theoretical basis of our hypothesis concerning the moderating role of perceived informational justice in the DG-job performance relationship is social exchange, a theory that has become one of the most common explanations for the effect of justice on work behaviour (Cropan- zano, Rupp, Mohler, \& Schminke, 2001). Blau (1964) proposed that the social exchange relationship depends on trust and obligations that are eventually fulfilled over the long term. He also suggested that fairness is a social norm through which people realise that current effort will be paid off in the future and that social exchange is based on reciprocity (Blau, 1964). From this theory we can infer that if people perceive fairness in their organisation or feel that their effort will be eventually be rewarded, they will try to work harder in exchange for a future return on their investment. With such an expectation of social exchange at work, high DG individuals will exercise their advantage in the ability to control themselves and wait longer in order to achieve a long-term goal; without an expectation of such an exchange, people will give up, regardless of whether their DG trait is high or low. Therefore, we propose the following:

Hypothesis 2: Perceived informational justice is a moderator in the DG-job performance relationship at 6 months, such that DG will be a stronger predictor of job performance for employees who perceive high informational justice than for those who perceive low perceived informational justice.

\section{Method}

\section{Participants and Procedure}

Data were collected during the recruitment process at four private and foreign IT companies located in three cities in China. All applicants were asked to complete a set of questionnaires during their interviews (Time 1), including a DG scale. We also measured Big Five personality traits as control variables because it has been shown that these traits influence employee performance (Barrick \& Mount, 1991; Robertson, Baron, Gibbons, MacIver, \& Nyfield, 2000). A total of 200 questionnaires were issued, and we recovered 178 valid questionnaires for a valid questionnaire rate of $89 \%$. Of all the applicants, $129(72.5 \%)$ were hired, and their DG scores were not significantly different from those of rejected ones. Three months after recruitment (Time 2), supervisors rated the new employees' job performance. The current analysis included only participants with both Time 1 and Time 2 data. The sample included 115 participants (53.0\% male) with an average age of 27.5 years $(S D=3.13)$. Their average amount of previous work experience was 54.09 months $(S D=$ 39.59 ), and $98.3 \%$ had a college diploma or higher degree. Twenty-nine supervisors completed the job performance questionnaire, and each supervisor evaluated between two and six employees $(M=4.0, S D=1.2)$. Five months after recruitment (Time 3), we asked these 115 new employees to complete another set of questionnaires, including an perceived informational justice scale. Supervisors of 70 of the employees ( $65 \%$ male) rated their performance again 6 months after recruitment (Time 4). Twenty-five supervisors evaluated between one and five employees $(M=2.9$, $S D=1.3)$ whose average age was 28.3 years $(S D=2.71)$. 
The final sample was 70 participants (67.1\% male), from whom data were collected at all four time points.

\section{Measures}

Delay of gratification. We selected 10 items from the Generalizability Deferment of Gratification Questionnaire (GDGQ; Ray \& Najman, 1986). The original GDGQ had 'yes' and 'no' ratings, but most subsequent research has used a Likert-type scale. Items (e.g., 'I enjoy a thing all the more because I have to wait for it or plan for it') were rated on a 7-point scale $(1=$ very strongly disagree, $7=$ very strongly agree). Cronbach's alpha was .64 in the present study.

Big Five Personality. We used Saucier's (1994) Big Five markers of 40 adjectives to tap the well-known five factors (extraversion, $\alpha=.71$; emotional stability, $\alpha=.76$; agreeableness, $\alpha=.75$; conscientiousness, $\alpha=.71$; and openness, $\alpha=71$ ). For each adjective, participants were asked to indicate the extent to which the target attribute applied to them, using a 9-point scale $(1=$ very strongly uncertain, $9=$ very strongly certain).

Job performance. We used Farh and Cheng's (1997) four-item, supervisor-rating performance scale (e.g., 'The extent to which the employee contributes to the overall performance of the team'). Supervisors rated their subordinates on a 5-point scale. The scale was developed using ratings of 990 Chinese participants, with evidence of good reliability and validity (Farh \& Cheng, 1997). In our study, the alpha coefficients for this scale at Time 2 and Time 4 were 0.82 and 0.72 respectively.

Perceived informational justice. We used the five-item Perceived Informational Justice Scale developed and validated by Colquitt (2001). Items (e.g., 'He/she communicated details in a timely manner') were rated on a 7-point scale $(1=$ very strongly disagree, $7=$ very strongly agree $)$. Cronbach's alpha was .80 in the present study.

\section{Results}

Table 1 displays the means, standard deviations, and correlations for the all variables. The results show that 3-month job performance was positively correlated with work experience $(r=.20, p<.05)$ and age $(r=.19, p<.01)$, and was also positively correlated with agreeableness $(r=.26$, $p<.01)$, conscientiousness $(r=.20, p<.05)$, and openness $(r=.29, p<.01)$. At Time $2(N=115), 3$-month job performance was positively correlated with DG $(r=.25$, $p<.01$ ). Among the 70 employees for whom data were collected at all four time points, 3-month job performance was also positively correlated with DG $(r=.28, p<.01)$. However, while their 6-month job performance was positively correlated with work experience $(r=.27, p<.01)$ and age $(r=.30, p<.01)$, it was not significantly correlated with DG. Six-month job performance was positively correlated with employees' perceived informational justice $(r=.27, p<.01)$. There was a significant moderate cor-



JOURNAL OF PACIFIC RIM PSYCHOLOGY 


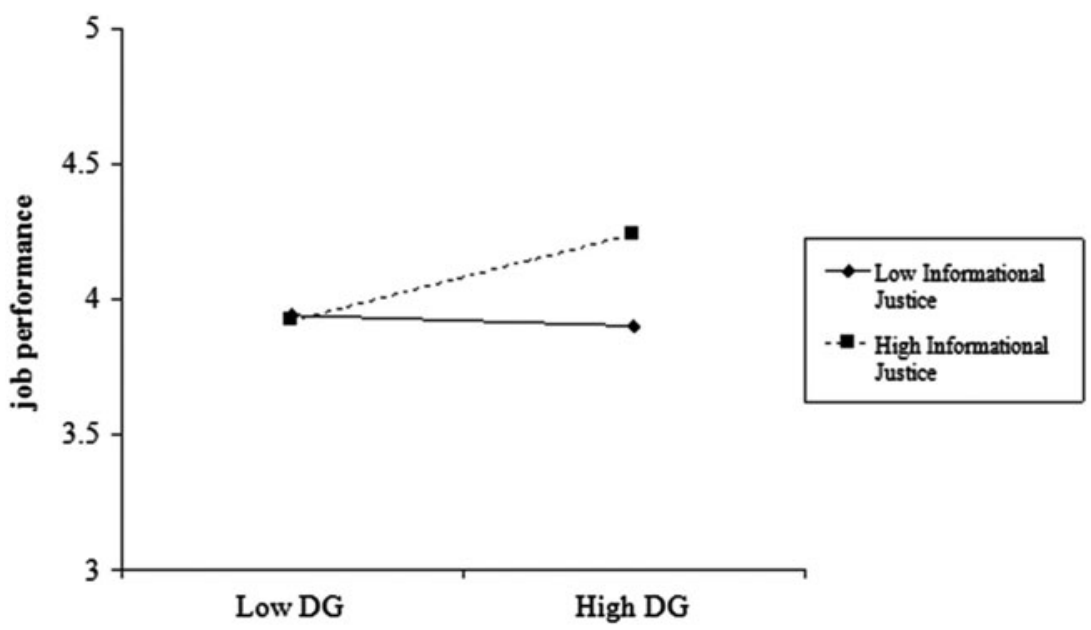

Figure 1

Interaction between DG and perceived informational justice on 6-month job performance.

relation between 3-month and 6-month job performance $(r=.54, p<.01$; see Table 1$)$.

We conducted hierarchical regression analyses to assess the function of DG in predicting new employees' job performance. DG was centred. As for 3-month job performance, step 1 included control variables including demographic characteristics (gender, age, educational background, and work experience) and Big Five personality traits. Step 1 did not reach statistical significance. In step 2, performance was regressed on DG. This step produced significant results, $R^{2}=.20, \Delta R^{2}=.05, F(10,114)=$ $2.60, p<.01$. DG was a significant predictor of 3-month job performance, such that as DG increased, so did job performance $(\beta=.19, p<.05)$. As for these new employees' 6-month job performance, step 1 included control variables, including demographic characteristics (gender, age, educational background, and work experience) and Big Five personality traits, and we also controlled for 3month job performance. Step 1 reached statistical significance, $R^{2}=.46, F(9,69)=5.86, p<.01$. Three-month job performance was a significant predictor of 6-month job performance $(\beta=.52, p<.01)$. In step 2,6 -month job performance was regressed on DG. This step also produced significant results, $R^{2}=.46, \Delta R^{2}=.00, F(10,69)=$ $5.19, p<.01$, but in this analysis, DG was not a significant predictor of 3-month job performance. Thus, Hypothesis 1 was supported.

We then tested the moderating role of perceived informational justice using hierarchical regression analyses. Perceived informational justice and DG were centred, and the interaction term was based on the product of these centred variables. As for perceived informational justice, in step 1, 6-month job performance was regressed on the control variables, including age, gender, education level, work experience, and Big Five personality traits. The results from step 1 did not reach statistical significance. In step 2, job performance was regressed on DG and per- ceived informational justice, and this step also did not show significance. In step 3, job performance was regressed on the interaction between DG and perceived informational justice. The result showed that the interaction term was a significant predictor of job performance, $R^{2}=.37$, $\Delta R^{2}=.17, F(9,69)=2.73, p<.05$ (see Figure 1). To examine the nature of these interactions, we conducted simple slope analyses. Among participants who scored high in perceived informational justice, DG was a relatively significant predictor of job performance $(\beta=.37, p<.05)$, but among those who scored low in perceived informational justice, DG was not a significant predictor of job performance $(\beta=-.11, p>.10)$. These findings support Hypothesis 2.

\section{Discussion}

Despite advances in understanding the effects of DG on long-term academic performance, no prior research has focused on DG's effect on job performance over time. In the present study, we used a longitudinal design to examine the predictive effect of DG on performance in the work place. Our hypotheses were supported, suggesting that DG can predict a new employee's job performance in an early period after entering a new organisation (at 3 months). However, as time passes, the DG-job performance relationship (at 6 months) changes depending on employees' perception of perceived informational justice. Particularly, we used multi-wave and multi-source data that provided causal evidence for our findings.

\section{Theoretical Implications}

This study contributes theoretically in two ways. Consistent with the DG academic performance literature (Duckworth \& Seligman, 2005; Mischel et al., 1988), the present research shows that DG has an effect on job performance at a workplace. In contrast to the well-established effect 
on children's performance years later, the DG effect on employees' performance works only for a relatively short period of time. Second, our study adds to research concerning which variables can predict both academic and job outcomes. A previous meta-analysis found that general cognitive ability predicts performance in both educational and work domains (Kuncel, Hezlett, \& Ones, 2004). Complementarily, our findings document that DG, as a personality trait, is a good predictor not only of academic performance but of job performance as well. DG may be a form of self-regulation involved in strategies such as controlling attention, managing emotional distraction, and persevering toward a goal (Mischel \& Mischel, 1983) that helps to transform motivation into performance (Vande Walle et al., 1999). In other words, our study supported the importance of DG for predicting work performance.

Empirically, this is the first study to test the longitudinal relationship between DG and job performance over a 6-month period of time in the workplace. The present research profiled a time-varying process during which DG's ability to predict job performance weakens over time. Importantly, we began the data collection during new entry (job interview) and continued observing the process over multiple months of employment. At the initial stage of entry, new employees had limited information about the organisations and were unlikely to know whether or not they would be treated fairly. Similar to the function of DG in the academic domain, where high DG students achieve more academic success than low DG students, high DG employees are generally more likely to display better job performance than low DG employees. However, the predictive effect of individual difference on job performance is stronger at organisational entry (Hesketh \& Neal, 1999) and weaker later on. Our study enriches the previous literature by uncovering a dynamic feature of the DG-job performance relationship.

Furthermore, our longitudinal research shows that perceived informational justice is an important moderator in the effect of DG on long-term job performance. When employees perceived high perceived informational justice, those with high DG showed better job performance than those with low DG; but when employees perceived low perceived informational justice, they showed a relatively low level of performance regardless of DG level. We explain this moderating role of perceived informational justice based on Mischel's (1974) theory that individuals will make decisions in line with their anticipation of certain rewards. That is to say, perceived informational justice may help employees think that they can get what they expect. This result is also consistent with previous research that found that explaining knowledge or information about delay rules helped children display effective delay behaviour (Mischel et al., 1988). Furthermore, our study contributes to understanding what types of situations impair the positive role of DG.
We found that with low perceived informational justice, even high DG individuals show a lower level of job performance. This finding calls for supervisors' urgent attention.

\section{Practical Implications}

With regard to practical significance, our findings suggest that DG could be used as a valid predictor of recruitees' later performance even after controlling for such personality factors as conscientiousness and agreeableness. Our findings also suggest that individuals with higher levels of DG may be more successful in their workplace performance. Notably, however, a boundary condition involving perceived informational justice exists for the effect of DG on job performance over time. Low perceived informational justice in an organisation appears to significantly reduce the usual effect of high DG on job performance. Specifically, perceiving low perceived informational justice may lead employees with high DG to perform no better than those with low DG, undoubtedly a disastrous situation from both recruitment and managerial perspectives. Perceived informational justice appears to be so important that supervisors should be encouraged to spend more time in communicating with new employees, especially high DG ones. For instance, they might explain procedures and rules thoroughly, such as how rewards are distributed; they may also provide timely information about such matters as vacancies and promotion opportunities.

In addition, we found that new employees' 3-month job performance could be predicted by DG, but job performance at 6 months could be predicted as a function of the interaction of DG and perceived informational justice, but not by DG alone. Thus, we presume the period of 3 to 6 months after first entry may be a critical time: new employees begin to form their view on whether their new working organisation is fair or not, and they re-estimate the value of working hard. Therefore, we strongly suggest that supervisors pay more attention to new employees during this period, as it may have a significant effect on employees' performance in the future.

\section{Limitations and Future Directions}

Clearly, one of the strengths of the present study is the multi-wave data collected at four time points during the process of newcomers' entry and adaptation. Such data is difficult to collect, and as a result the first limitation is our relatively small sample size. Future studies should attempt to test our findings in a larger and more heterogeneous sample for which HLM can be adapted to test models of within-individual change over time. Second, since we followed newcomers' performance for 6 months, we can conclude that perceived informational justice moderates the DG-performance relationship in that particular period only, a very short time at the very beginning of entering a new organisation. Future research should follow employees for a longer time to verify this effect and also to 
examine the possible moderating roles of procedural, distributive, and interpersonal justice over a longer period. Third, job performance contains a variety of elements, but we used only subjective ratings by supervisors. In the future, objective and more diverse measurements would strengthen validity. Finally, further study might examine the mechanism(s) of the relationship between DG and job performance from various angles, including impression management.

Previous research has indicated that DG has a greater effect on predicting students' academic performance than IQ does, but we did not examine the effect of employees' IQ on their job performance. Future research should pay more attention to differential effects of DG and IQ on employees' job performance and whether self-control is more important or influential than intellectual factors in predicting performance, especially in work-related domains. Finally, future research may consider including more possible influences on employees performance, such as contextual performance. Delay of gratification may be connected with, for example, prosocial or affiliative forms of contextual performance, such as helping a colleague.

\section{References}

Ayduk, O. (2007). Construing persons in context: On building a science of the individual. In Y. Shoda, D. Cervone, \& G. Downey (Eds.), Persons in context: Building a science of the individual (pp. 97-108). New York: Guilford Press.

Barrick, M.R., \& Mount, M.K. (1991). The Big Five personality dimensions and job performance: A meta-analysis. Personnel Psychology, 44, 1-26.

Baumeister, R.F., \& Vohs, K.D. (2003). Willpower, choice, and self-control. In R.F. Baumeister \& J. Tierney (Eds.), Will power: Rediscovering the greatest human strength (pp. 201216). New York, NY: Penguin Press.

Bies, R.J. (2001). Interactional (injustice: The sacred and the profane. In J. Greenberg \& R. Cropanzano (Eds.), Advances in organizational justice (pp. 89-118). Stanford, CA: Stanford University Press.

Bies, R.J., \& Moag, J.F. (1986). Interactional justice: Communication criteria of fairness. In R.J. Lewicki, B.H. Sheppard, \& M.H. Bazerman (Eds.), Research on negotiations in organizations (vol. 1, pp. 43-55). Greenwich, CT: JAI Press.

Blau, P. (1964). Exchange and power in social life. New York, NY: Wiley.

Callan, M., Shead, N., \& Olson, J. (2009). Foregoing the labor for the fruits: The effect of just world threat on the desire for immediate monetary rewards. Journal of Experimental Social Psychology, 45, 246-249.

Colquitt, J. (2001). On the dimensionality of organizational justice: A construct validation of a measure. Journal of Applied Psychology, 86, 386-400.

Colquitt, J.A., Greenberg, J., \& Zapta, C. (2005). What is organizational justice? A historical overview. In J. Greenberg \& J.A. Colquitt (Eds.), Handbook of organizational justice (pp. 3-56). Mahwah, NJ: LEA.
Cropanzano, R., Byrne, Z.S., Bobocel, D.R., \& Rupp, D.E. (2001). Moral virtues, fairness heuristics, social entities, and other denizens of organizational justice. Journal of Vocational Behavior, 58, 164-209.

Cuskelly, M., Airong Zhan, M., \& Hayes, A. (2003). A mental age-matched comparison study of delay of gratification of children with Down syndrome. International Journal of Disability Development and Education, 50, 239252.

Duckworth, A.L., \& Seligman, M.E. (2005). Self-discipline outdoes IQ in predicting academic performance of adolescents. Psychological Science, 16, 939-944.

Farh, J., \& Cheng, B. (1997). Modesty bias in self-ratings in Taiwan: Impact of item wording, modesty value, and selfesteem. Chinese Journal of Psychology, 39, 103-118.

Fishbach, A., \& Trope, Y. (2005). The substitutability of external control and self-control. Journal of Experimental Social Psychology, 41, 256-270.

Greenberg, J. (1990). Organizational justice: Yesterday, today, and tomorrow. Journal of Management, 16, 399-432.

Henry, R.A., \& Hulin, C.L. (1987). Stability of skilled performance across time: Some generalizations and limitations on utilities. Journal of Applied Psychology, 72, 457-462.

Hesketh, B., \& Neal, A. (1999). Technology and performance. In D.R. Ilgen \& E.D. Pulakos (Eds.), The changing nature of performance: Implications for staffing, motivation, and development (pp. 21-55). San Francisco, CA: Jossey-Bass.

Joy, V.L., \& Witt, L.A. (1992). Delay of gratification as a moderator of the procedural justice distributive justice relationship. Group \& Organization Management, 17, 297-308.

Konovsky, M., \& Pugh, D. (1994). Citizenship behavior and social exchange. Academy of Management Journal, 37, 656669.

Kuncel, N.R., Hezlett, S.A., \& Ones, D.S. (2004). Academic performance, career potential, creativity, and job performance: Can one construct predict them all? Journal of Personality and Social Psychology, 86, 148-186.

Lindebaum, D. (2013). Does emotional intelligence moderate the relationship between mental health and job performance? An exploratory study. European Management Journal, 31, 538548.

Liu, X., Wang, L., \& Liao, J. (2016). Enabling delay of gratification behavior in those not so predisposed: The moderating role of social support. Frontiers in Psychology, 7,1-12.

Miller, M., Woehr, D., \& Hudspeth, N. (2002). The meaning and measurement of work ethic: Construction and initial validation of a multidimensional inventory. Journal of Vocational Behavior, 60, 451-489.

Mischel, W. (1974). Processes in delay of gratification. Advances in Experimental Social Psychology, 249-258.

Mischel, W. (1996). From good intentions to willpower. In P.M. Gollwitzer \& J.A. Bargh (Eds.), The psychology of action: Linking cognition and motivation to behavior (pp. 197-218). New York, NY: Guilford Press.

Mischel, W., Cantor, N., \& Feldman, S. (1996). Principles of self-regulation: The nature of willpower and self-control. In 
E.T. Higgins \& A.W. Kruglanski (Eds.), Social psychology: Handbook of basic principles (pp. 329-360). New York, NY: Guilford Publications.

Mischel, W., \& Mischel, H.N. (1983). The development of children's knowledge of self-control strategies. Child Development, 54, 603-619.

Mischel, W., Shoda, Y., \& Peake, P. (1988). The nature of adolescent competencies predicted by preschool delay of gratification. Journal of Personality and Social Psychology, 54, 687-696.

Murphy, K.R. (1989). Is the relationship between cognitive ability and job performance stable over time? Human Performance, 2, 183-200.

Porath, C.L., \& Bateman, T.S. (2006). Self-regulation: From goal orientation to job performance. Journal of Applied Psychology, 91, 185-192.

Ray, J., \& Najman, J. (1986). The generalizability of deferment of gratification. Journal of Social Psychology, 126, 117-119.

Robertson, I.T., Baron, H., Gibbons, P., MacIver, R., \& Nyfield, G. (2000). Conscientiousness and managerial performance. Journal of Occupational and Organizational Psychology, 73, 171-180.
Saucier, G. (1994). Mini-markers: A brief version of Goldberg's unipolar Big-Five markers. Journal of Personality Assessment, 63, 506-516.

Shoda, Y., Mischel, W., \& Peake, P. (1990). Predicting adolescent cognitive and self-regulatory competencies from preschool delay of gratification: Identifying diagnostic conditions. Developmental Psychology, 26, 978-986.

Strakowski, S.M., Fleck, D.E., DelBello, M.P., Adler, C.M., Shear, P.K., McElroy, S.L., ... Arndt, S. (2010). Characterizing impulsivity in mania. Bipolar Disorders, 12, 285-297.

Tyler, T.R., \& Lind, E.A. (1992). A relational model of authority in groups. In M.P. Zanna (Ed.), Advances in experimental social psychology (vol. 25, pp. 115-191). San Diego, CA: Academic Press.

VandeWalle, D., Brown, S.P., Cron, W.L., \& Slocum Jr, J.W. (1999). The influence of goal orientation and self-regulation tactics on sales performance: A longitudinal field test. Journal of Applied Psychology, 84, 249-259.

Witt, L. (1990). Delay of gratification and locus of control as predictors of organizational satisfaction and commitment: Sex differences. The Journal of General Psychology, 117, $437-446$. 